\title{
Detection of a Protein-Acetaldehyde Adduct in the Liver of Rats Fed Alcohol Chronically
}

\author{
Renee C. Lin, Rebecca S. Smith, and Lawrence Lumeng \\ Departments of Medicine and Biochemistry, Indiana University School of Medicine, Indianapolis, Indiana 46223, \\ and the Veterans Administration Medical Center, Indianapolis, Indiana 46202
}

\begin{abstract}
We report here the formation in vivo of a protein-acetaldehyde adduct (protein-AA) in liver when rats were fed alcohol chronically. This chemically modified protein was demonstrated by electroimmunotransblot technique and with rabbit polyclonal antibodies that recognize acetaldehyde adduct as an epitope (i.e., both anti-hemocyanin-AA IgG and anti-myoglobin-AA IgG). It has a molecular weight of 37,000 . It can be detected in the liver of rats fed the alcohol-containing American Institute of Nutrition 1976 liquid diet for only 1 wk. Since the protein profiles of soluble hepatic proteins from alcohol-fed and control rats were identical on SDS-PAGE, the peroxidase-positive band demonstrated by electroimmunotransblot was most likely not a new protein synthesized de novo. Borohydride reduction was not necessary to stabilize this protein-AA. Intraperitoneal injections of ethanol ( $2 \mathrm{~g} / \mathrm{kg}$ body wt) at 8 -h intervals to rats over a 24-h period did not produce any detectable protein-AA in the liver. Incubation of the liver homogenate from a control liver with acetaldehyde without sodium cyanoborohydride for 4 $h$ also failed to generate any protein-AA. Therefore, the formation of the $37-\mathrm{kD}$ protein-AA in vivo reported here is dependent on chronic alcohol consumption.
\end{abstract}

\section{Introduction}

Ethanol is oxidized to acetaldehyde mainly in the liver via alcohol dehydrogenase; the latter metabolic intermediate in turn is further oxidized by aldehyde dehydrogenase to form acetate. Acetaldehyde has been implicated in a number of actions of alcohol as well as hepatotoxicity due to alcohol consumption $(1,2)$. A number of studies in vitro have shown that acetaldehyde can bind to plasma proteins (3), albumin $(3,4)$, erythrocyte membrane proteins $(5)$, tubulin $(6,7)$, hepatic proteins $(8,9)$, a number of enzymes with critical lysine resi-

Address reprint requests to Dr. Renee C. Lin, Medical Research (151), Veterans Administration Medical Center, 1481 West 10th Street, Indianapolis, IN 46202.

A preliminary report of our findings was presented at the JointMeeting of the American Gastroenterological Association, American Association for the Study of Liver Diseases, and the Gastroenterology Research Group in Chicago, 10-3 May 1987 (Gastroenterology. 92:1751).

Received for publication 9 July 1987 and in revised form 28 September 1987.

The Journal of Clinical Investigation, Inc.

Volume 81, February 1988, 615-619 dues (10), and to hemoglobin $(3,11,12)$. The exact chemical structure of these protein-acetaldehyde adducts (proteinAAs) ${ }^{1}$ has not been fully delineated but the interaction is likely to involve, at least in part, Schiff's base formation $(4,12,13)$. Whether proteins can form adducts with acetaldehyde generated from ethanol in vivo has not been demonstrated.

Recently, Israel and his co-workers (14) reported that mice given alcohol-containing drinking water chronically developed serum antibodies that reacted against protein-AAs. Furthermore, Hoerner et al. (15) reported that the titers of anti-protein-AA immunoglobulins are higher in sera of alcoholic patients than those of healthy, nondrinking individuals. These studies strongly suggest the formation of immunogenic protein-AAs in vivo when animals or humans consume alcohol chronically. We report in this paper the detection of a proteinAA in the liver of alcohol-fed rats. To our knowledge, this is the first such report.

\section{Methods}

Preparation of protein-AAs. Human hemoglobin was prepared from fresh human blood as described (11). Keyhole limpet hemocyanin, sperm whale myoglobin, and bovine serum IgG were purchased from Sigma Chemical Co. (St. Louis, MO). Each protein (10 mg) was dissolved in $2.5 \mathrm{ml}$ of $50 \mathrm{mM}$ phosphate buffer (pH 7.0). Acetaldehyde and sodium cyanoborohydride $\left(\mathrm{NaCNBH}_{3}\right)$ were then added to each protein solution to final concentrations of 250 and $100 \mathrm{mM}$, respectively. The protein mixtures were incubated at room temperature for 4 h. Each mixture was then chromatographed on a PD-10 column (Sephadex G-25M; Pharmacia Fine Chemicals, Division of Pharmacia Inc., Piscataway, NJ) to remove reagents. Each protein-AA was finally eluted with $0.15 \mathrm{M} \mathrm{NaCl}$ containing $10 \mathrm{mM}$ phosphate, $\mathrm{pH} 7.0$ (PBS). Protein-AA solutions were aliquoted and stored at $-70^{\circ} \mathrm{C}$.

Preparation of anti-protein-AA IgG. We used the method described by Israel et al. (14). Hemocyanin-AA $(200 \mu \mathrm{g})$ was mixed with Freund's complete adjuvant and injected into a New Zealand White rabbit. Two or three more booster shots with the same amount of the protein-AA, emulsified in Freund's incomplete adjuvant, were given to the rabbit at 3-wk intervals. A small amount of blood was taken from an ear vein of the rabbit to test for immunoreactivity 1 wk after each booster shot. When immunoreactivity was demonstrated, blood (100-120 ml) was then collected from the rabbit by cardiac puncture and the rabbit was killed. Blood was allowed to clot at room temperature for $30 \mathrm{~min}$ and the serum was separated from the clot. Serum IgG was purified by a Protein A Sepharose CL-4B column (Pharmacia Fine Chemicals). The IgG fraction was then chromatographed on PD-10 column as described above and eluted with PBS. The final product was aliquoted

1. Abbreviations used in this paper: AA, acetaldehyde adduct; EITB, electroimmunotransblot; NCP, nitrocellulose paper. 
and stored at $-70^{\circ} \mathrm{C}$. Antibodies against myoglobin-AA was prepared in the same manner.

Animal procedures. Male Wistar rats (initial body weights ranged from 200 to $225 \mathrm{~g}$ ) were pair-fed the alcohol-containing and the control AIN'76 (BioServ, Frenchtown, NJ) liquid diets for up to $7 \mathrm{wk}$. At the end of the feeding period, all the rats were killed. Their livers were removed and frozen immediately in liquid nitrogen and stored at $-70^{\circ} \mathrm{C}$ until use.

Electroimmunotransblot (EITB) procedure. Soluble rat liver proteins were separated by SDS-PAGE using $7.5 \%$ acrylamide (16). EITB procedures were essentially the same as described by Tsang et al. (17).

\section{Results}

Ouchterlony double immunodiffusion. The specificities of each rabbit antibody were tested by Ouchterlony double immunodiffusion. Fig. 1 shows that the rabbit anti-hemocyanin-AA. IgG formed strong precipitation lines with hemocyanin-AA, myoglobin-AA, bovine IgG-AA, and human hemoglobin-AA (wells 1-4). The anti-hemocyanin-AA IgG also reacted with hemocyanin (well 5) but not with the other unmodified proteins (wells 6-8). Similarly, rabbit anti-sperm whale myoglobin-AA IgG recognized all four protein-AAs tested as well as myoglobin but not the other unmodified proteins (data not shown).

SDS-PAGE and EITB of soluble liver proteins from rats fed alcohol-containing diet chronically. Frozen liver samples (200 $\mathrm{mg}$ ) from rats that had been fed American Institute of Nutri-

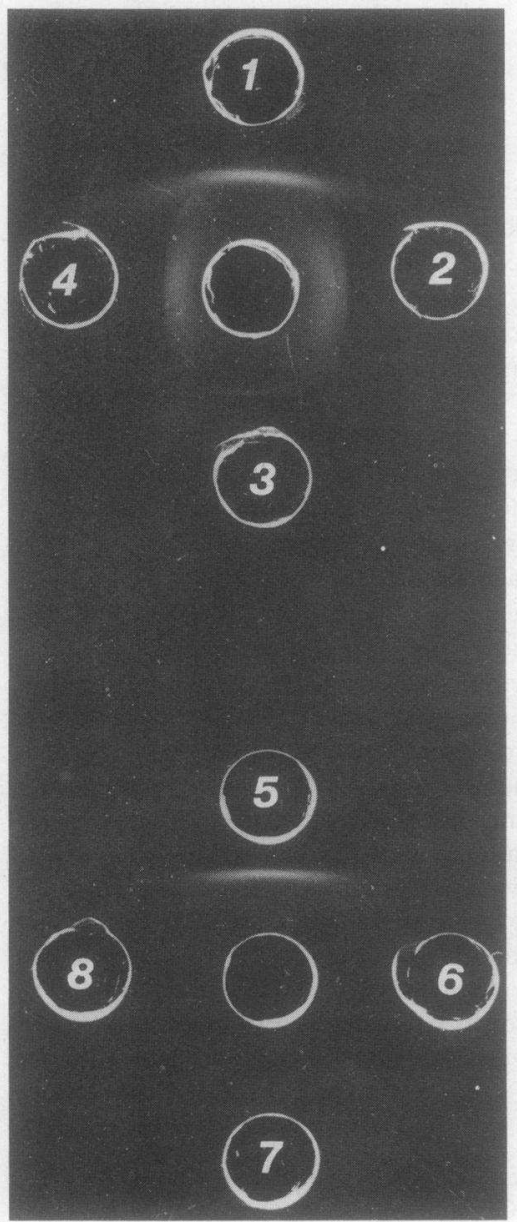

Figure 1. Ouchterlony double immunodiffusion. Protein-AAs and anti-hemocyanin-AA IgG were prepared as described in the Methods section. Center wells contained $60 \mu \mathrm{g}$ of rabbit anti-hemocyanin-AA IgG. Outer wells (labeled 1 to 8 ) contained $3 \mu \mathrm{g}$ of antigen proteins in each well. 1, hemocyaninAA; 2, myoglobin-AA; 3 , bovine IgG-AA; 4 , human hemoglobinAA; 5 , hemocyanin; 6 , myoglobin; 7 , bovine IgG; 8 , human hemoglobin.

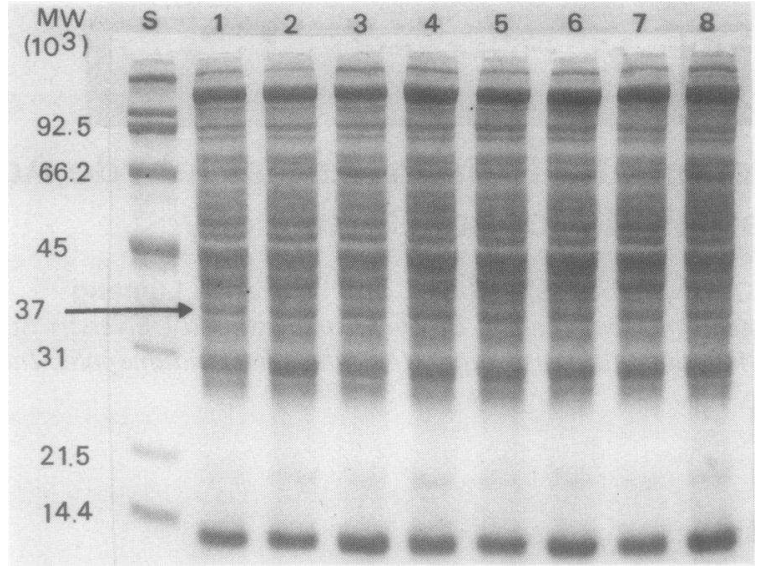

Figure 2. SDS-PAGE of rat liver soluble proteins. Rats had been pair-fed the alcohol-containing and the alcohol-free AIN'76 liquid diets for $7 \mathrm{wk}$. Liver homogenates were centrifuged at $435,000 \mathrm{~g}$ for $12 \mathrm{~min}$ to remove insoluble proteins. Samples containing $200 \mu \mathrm{g}$ protein were loaded onto each lane. The gel was stained with Coomassie Blue for proteins. Odd number lanes are from alcohol-fed rats and even numbers from control rats. Lane $S$ represents molecular weight standards.

tion 1976 (AIN '76) liquid diet for $7 \mathrm{wk}$ were homogenized in $3 \mathrm{ml}$ of PBS using a homogenizer (Polytron Corp., Elkhart, IN). The homogenates were then centrifuged at $435,000 \mathrm{~g}$ for 12 min in a model TL-100 table top ultracentrifuge (Beckman Instruments, Palo Alto, CA) to remove insoluble particles. Soluble liver proteins were separated by SDS-PAGE and stained with Coomassie Blue. As shown in Fig. 2, the profile of soluble liver proteins from rats that had been fed the alcohol-containing diet was identical to that of rats fed the control diet. When liver proteins were transferred from the polyacrylamide gel to nitrocellulose paper (NCP) and then immunoblotted, a distinct peroxidase positive band from liver extracts of the alcohol-fed rats appeared on NCP, indicating the presence of a

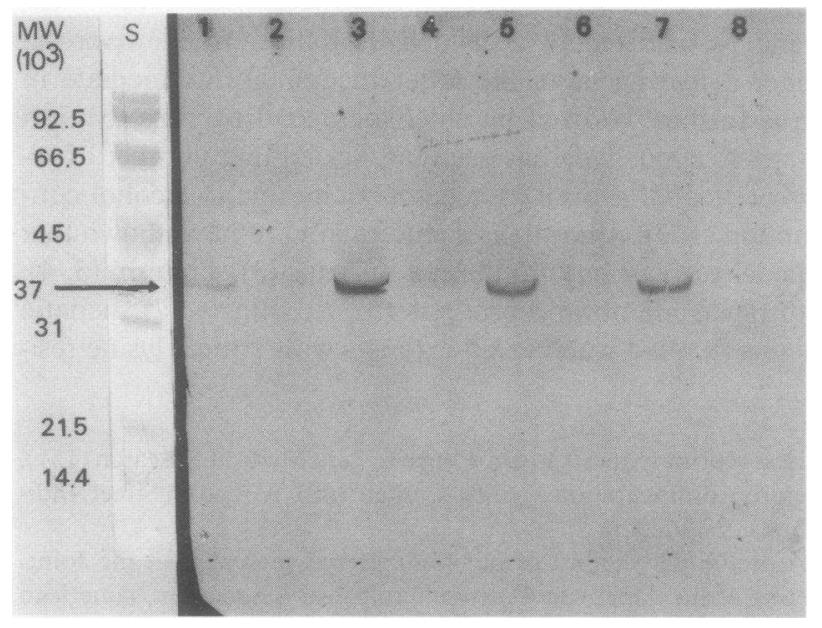

Figure 3. EITB of rat liver soluble proteins. Proteins from a SDSPAGE gel identical to that of Fig. 2 were transferred (Western transfer) to a piece of NCP and immunoblotted with anti-hemocyanin-AA lgG as described in Methods. Molecular weight standards $(S)$ were stained with Amido Black for proteins. The odd number samples are from alcohol-fed rats and the even number samples from control-fed rats. 
protein-AA (Fig. 3). This protein-AA was seen in four of five alcohol-fed rats. None of the liver samples from their pair-fed controls exhibited this specific immunoreactivity (Fig. 3). The molecular weight of the protein-AA detected here was calculated to be 37,000. A similar experiment was performed using animals that had been fed the alcohol liquid diet for only $1 \mathrm{wk}$. Two of the four rats fed the alcohol-containing diet showed the $37-\mathrm{kD}$ protein-AA. However, in another experiment that involved five alcohol-fed rats, all five rats developed the $37-\mathrm{kD}$ protein-AA after they had been fed the alcohol-containing diet for 2 wk.

Effect of borohydride reduction on the $37-k D$ liver protein$A A$ of the alcohol-fed rat. Liver homogenates from the liver of a rat fed the alcohol-containing diet for $7 \mathrm{wk}$ were treated with and without $100 \mathrm{mM} \mathrm{NaCNBH}_{3}$ by incubating them at room temperature for $4 \mathrm{~h}$ before centrifugation at $12,000 \mathrm{~g}$ for $2 \mathrm{~min}$ to remove cellular debris. These crude homogenates were further centrifuged at $435,000 \mathrm{~g}$ for $12 \mathrm{~min}$ to prepare soluble supernatants. All preparations were then applied to Sephadex G-25M chromatography columns to remove $\mathrm{NaCNBH}_{3}$. Protein concentrations of these liver preparations were determined by the method of Lowry et al. (18). Equal amounts (200 $\mu \mathrm{g})$ of proteins from each preparation were used for the EITB experiment. We found that the color intensity of the hepatic protein-AA band on NCP was not affected by borohydride treatment. The protein-AA was detected in both the crude homogenate and the soluble supernatants. We also found that there was no decrease in the protein-AA intensity when protein preparations had been stored at $0^{\circ} \mathrm{C}$ overnight.

EITB of rat liver proteins with rabbit anti-myoglobin-AA $\operatorname{Ig} G$. Soluble rat liver proteins were immunotransblotted with rabbit anti-myoglobin-AA IgG. These results were similar to those obtained with rabbit anti-hemocyanin-AA IgG; only one specific peroxidase positive band corresponding to a $37-\mathrm{kD}$ protein was visible with hepatic proteins obtained from an alcohol-fed rat (Fig. 4). No peroxidase positive band could be detected when unimmunized rabbit $\operatorname{IgG}$ was used instead of rabbit anti-protein-AA IgG.

Intraperitoneal injections of ethanol. 12 rats were given intraperitoneal injections of ethanol $(2 \mathrm{~g} / \mathrm{kg}$ body wt) at $8-\mathrm{h}$ intervals over a period of $24 \mathrm{~h}$. Four rats were killed every $8 \mathrm{~h}$ to prepare soluble liver proteins. When tested with the EITB method, none of these rats showed evidence of any liver protein-AA formation by this treatment.

In vitro incubation of liver proteins with acetaldehyde. Soluble liver proteins were prepared from a control rat in PBS containing $0.1 \%$ sodium azide. The protein solution was aliquoted and incubated for $4 \mathrm{~h}$ in the absence and presence of acetaldehyde at 1 or $2.5 \mathrm{mM}$. Many liver proteins including the 37- $\mathrm{kD}$ band formed protein-AAs when these high concentrations of acetaldehyde were used and when $\mathrm{NaCNBH}_{3}$ was also present (Fig. 5, lanes $I$ and 2). However, no protein-AA could be detected by the EITB method when liver proteins were incubated with 1-2.5 mM acetaldehyde at room temperature for $4 \mathrm{~h}$ (Fig. 5, lanes 4 and 5 ) or at $37^{\circ} \mathrm{C}$ for as long as 24 h (Fig. 5, lane 6 and 7) if $\mathrm{NaCNBH}_{3}$ was not present.

\section{Discussion}

This is the first report that documents unequivocally the formation of a hepatic protein-AA in vivo during chronic alcohol feeding. This hepatic protein-AA has an apparent molecular

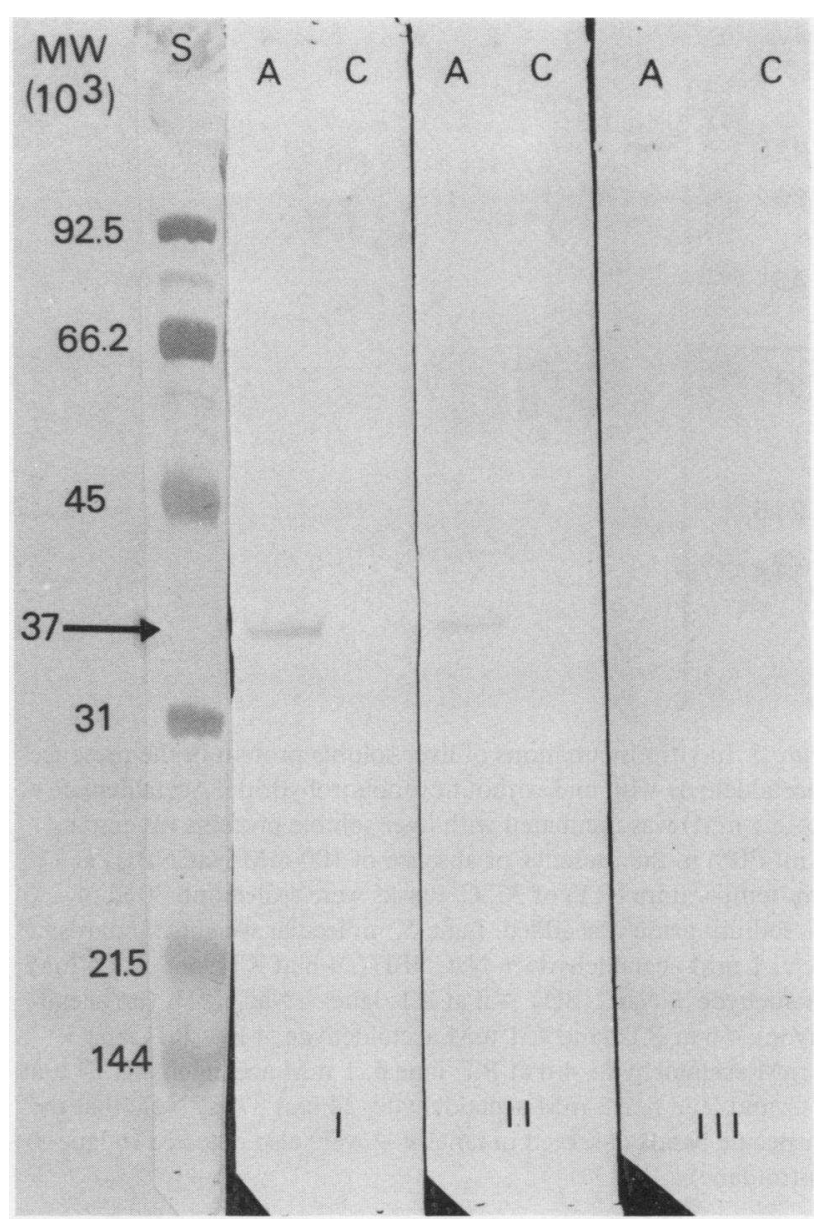

Figure 4. EITB of rat liver soluble proteins with various anti-AAprotein antibodies. Procedures for EITB were performed as described in Methods. Hepatic soluble proteins were prepared from a rat fed alcohol-containing AIN'76 liquid diet for 7 wk $(A)$ and its pair-fed control $(C)$. Molecular weight standards $(S)$ were stained with Amido Black. Lane I, EITB with rabbit anti-hemocyanin-AA IgG; lane $I I$, EITB with rabbit anti-myoglobin-AA IgG; and lane $I I I$, EITB with rabbit control (nonimmunized) serum IgG.

weight of 37,000 . On SDS-PAGE and protein staining, the protein-AA that we detected on EITB did not represent a new band but corresponded to a well-delineated protein band that can be seen in liver soluble proteins of both the alcohol-fed and the control rats. Therefore the protein-AA is not a newly synthesized protein, but is derived posttranslationally.

Immunologic approach was employed in this study to detect the formation of protein-AAs because this approach is very sensitive. At least three pieces of evidence indicate that this approach is also specific: (a) keyhole limpet (snail) hemocyanin, sperm whale myoglobin (or human hemoglobin), and bovine IgG are very dissimilar proteins. Mere denaturation of these proteins due to changes in their secondary, tertiary, or quarternary structures which might take place in the presence of high concentrations of acetaldehyde for preparing the protein-AAs is not likely to cause them to cross-react (Fig. 1, wells 1-4). The best explanation for the cross-reactions shown in Fig. 1 (wells 1-4) is recognition of the acetaldehyde adducts in these modified proteins as epitopes by anti-hemocyanin-AA IgG (Fig. 1, center wells). (b) The 37-kD hepatic protein-AA was detected by using both anti-hemocyanin-AA IgG and 


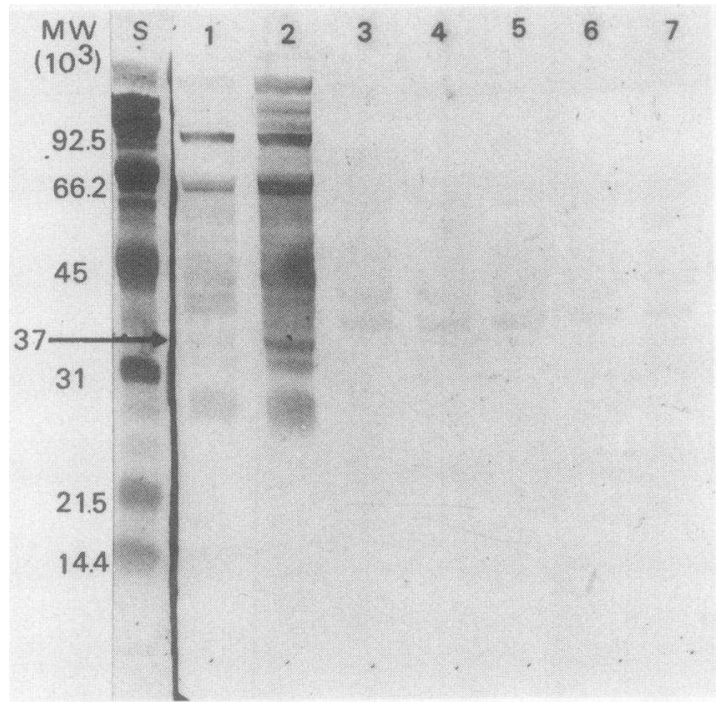

Figure 5. In vitro incubations of liver soluble protein in the presence of acetaldehyde with and without cyanoborohydride. Acetaldehyde ( 0 to $2.5 \mathrm{mM})$ was incubated with liver soluble proteins $(21 \mathrm{mg}$ in $3.0 \mathrm{ml}$ PBS) in the presence or absence of $100 \mathrm{mM} \mathrm{NaCNBH}_{3}$ at room temperature $(\mathrm{RT})$ or $37^{\circ} \mathrm{C}$. Flasks were sealed and $30 \mu \mathrm{l}$ of $10 \%$ sodium azide was added. Lane $S$, molecular weight standards; lane $1,1 \mathrm{mM}$ acetaldehyde $+\mathrm{NaCNBH}_{3}, 4 \mathrm{~h}$ at RT; lane $2,2.5 \mathrm{mM}$ acetaldehyde $+\mathrm{NaCNBH}_{3}, 4 \mathrm{~h}$ at RT; lane 3, $\mathrm{NaCNBH}_{3}$ (no acetaldehyde), $4 \mathrm{~h}$ at RT; lane $4,1 \mathrm{mM}$ acetaldehyde, $4 \mathrm{~h}$ at RT; lane 5 , $2.5 \mathrm{mM}$ acetaldehyde, $4 \mathrm{~h}$ at $\mathrm{RT}$; lane $6,1 \mathrm{mM}$ acetaldehyde, $24 \mathrm{~h}$ at $37^{\circ} \mathrm{C}$; and lane $7,2.5 \mathrm{mM}$ acetaldehyde, $24 \mathrm{~h}$ at $37^{\circ} \mathrm{C}$. Note that the nonspecific bands observed in lanes 4-7 were also detected in lane 3 (control lane).

anti-myoglobin-AA IgG (Fig. 4). This finding further suggests that acetaldehyde adduct is the common epitope recognized by both IgG antibodies. (c) Additionally, we have shown in preliminary studies that poly-lysine-AA can compete against the binding of anti-hemocyanin-AA Ig to the $37-\mathrm{kD}$ liver protein$\mathrm{AA}$, indicating that acetaldehyde adduct is the epitope.

Several studies in vitro have shown that acetaldehyde can bind to proteins to form both stable and unstable adducts (4, $12,13)$. The unstable adducts (Schiff's base) can be stabilized by various reducing agents $(4,12,13)$. We found that the 37-kD liver protein-AA detected in vivo was stable without further reduction by sodium cyanoborohydride. Therefore, it appears that this protein reacts with acetaldehyde generated from ethanol in vivo and then forms either a stable adduct spontaneously or an adduct that becomes stabilized by some endogenous reducing agents such as ascorbic acid (13). We found no protein-AA formation when liver homogenate was incubated in vitro with acetaldehyde at concentrations as high as $2.5 \mathrm{mM}$ (a high, unphysiological concentration) and in the absence of any reducing agent overnight. Acute exposure to alcohol in vivo by injecting multiple doses of ethanol to rats intraperitoneally for $24 \mathrm{~h}$ also did not elicit any detectable protein-AA band in the liver. However, the $37-\mathrm{kD}$ hepatic protein-AA can be detected in rats fed the alcohol-containing liquid diet for only $1 \mathrm{wk}$. Therefore, the formation of the 37-kD liver protein-AA occurs only with chronic alcohol feeding for at least $1 \mathrm{wk}$.

The finding of only one protein-AA in the livers of rats fed the alcohol-containing diet for as long as $7 \mathrm{wk}$ suggests that the adduct formation is selective and is not indiscriminate. The reason for this selectivity is uncertain and is currently under investigation. It should be pointed out that the AIN'76 liquid diet used in this study, when compared with the original Lieber-DeCarli diet (19), contains less fat and more protein. Additionally, it is known that feeding the AIN'76 alcohol diet to rats (in contrast to feeding the original Lieber-DeCarli diet) does not lead to persistently elevated blood alcohol concentration (20) and does not produce fatty liver (Lin, R. C., L. Lumeng, and V. L. Phelps, manuscript submitted for publication). It remains to be studied whether more liver protein-AAs can be detected if rats were fed the original Lieber-DeCarli diet (19). Besides the possibility that the diet might be a factor, there may be other explanations for finding only one proteinAA in the liver of rats fed ethanol chronically. It is possible that the EITB method we used was not sensitive enough to detect other protein-AAs that may form in much lower concentrations. It is also possible that all protein-AAs except the $37-\mathrm{kD}$ protein-AA degrade more rapidly than their corresponding unmodified parent proteins. Accordingly, if the $37-\mathrm{kD}$ proteinAA is more stable than other proteins-AAs, it will accumulate and can be detected more readily by the EITB method used here.

It has been postulated that acetaldehyde can react with proteins by the formation of carbinolamines, Schiff's bases, thioacetals, and disubstituted adducts. It is possible that the kind of adducts formed may depend on the concentration of acetaldehyde present in the reaction system. Unfortunately, except for hemoglobin (see below), little is known at present about the precise chemical modifications that can take place with acetaldehyde in any given protein in vitro or in vivo. Which amino acid in the 37-kD liver protein reacts with acetaldehyde has not been determined. The anti-hemocyanin-AA IgG and anti-myoglobin-AA IgG used in this study were prepared according to the method of Israel et al. (14). These investigators have shown that the anti-hemocyanin-AA IgG recognized only the poly-(L-lysine)-acetaldehyde adducts when tested against poly-(L-lysine), poly-(L-tyrosine), and poly-(Lvaline) condensates. However, our results showed the $37-\mathrm{kD}$ liver protein-AA could also be detected by rabbit anti-myoglobin-AA IgG (Fig. 4). Hemoglobin has been shown to form stable adducts with acetaldehyde in vitro at neutral $\mathrm{pH}(21)$. The sites of attachment of the acetaldehyde to human hemoglobin have been shown to be the free amino groups of the $\mathrm{NH}_{2}$-terminal value residues of the $\alpha$ and $\beta$ chains (22). Since myoglobin, similar to hemoglobin, also contains $\mathrm{NH}_{2}$-terminal valines (22), it is possible that the recognition of this $37-\mathrm{kD}$ protein-AA by anti-myoglobin-AA IgG is due to acetaldehyde adducts formation at the valine sites of the protein. It remains to be studied whether the acetaldehyde reactive sites of the 37-kD liver protein-AA represent lysines or valines or both.

The possible consequence of the formation of adducts between acetaldehyde and the liver protein is of great interest. Acetaldehyde has been shown to covalently bind to tubulin and results in complete inhibition of microtubule formation $(6,7)$. Our preliminary data show that this $37-\mathrm{kD}$ protein is located in cytosol. Based on the molecular weight, the 37-kD liver protein is neither tubulin nor albumin. Work is underway to identify this protein. It is worthwhile to point out that we have not excluded the possibility that membrane-bound proteins, (e.g., proteins in plasma membrane or membranes of intracellular organelles) can also form protein-AAs. Detailed studies will need to be done to examine this possibility with the 
present EITB technique or with even more sensitive approaches.

\section{Acknowledgments}

This research is supported by National Institute on Alcohol Abuse and Alcoholism grant R23AA06991-01 and Veterans Administration Research Funds.

\section{References}

1. Sorrell, M. F., and D. J. Tuma. 1985. Hypothesis: alcoholic liver injury and the covalent binding of acetaldehyde. Alcohol. Clin. Exp. Res. 9:306-309.

2. Salaspuro, M., and K. Lindro. 1985. Metabolism and toxicity of acetaldehyde. In Alcohol Related Diseases in Gastroenterology. H. K. Seitz and B. Kommerell, editors. Springer-Verlag, Berlin/Heidelberg. 106-123.

3. Lumeng, L., R. Minter, and T. K. Li. 1982. Distribution of stable acetaldehyde adducts in blood under physiological conditions. Fed. Proc. 41:765.

4. Donohue, T. M., D. J. Tuma, and M. F. Sorrell. 1983. Acetaldehyde adducts with proteins: binding of ${ }^{14} \mathrm{C}$-acetaldehyde to serum albumin. Arch. Biochem. Biophys. 220:239-246.

5. Gaines, K. C., J. M. Salhany, D. J. Tuma, and M. F. Sorrell. 1977. Reactions of acetaldehyde with human erythrocyte membrane proteins. FEBS (Fed. Eur. Biochem. Soc.) Lett. 75:115-119.

6. Jennett, R. B., D. J. Tuma, and M. F. Sorrell. 1980. Effect of ethanol and its metabolites on microtubule formation. Pharmacology (Basel). 21:363-368.

7. Jennett, R. B., E. L. Johnson, M. F. Sorrell, and D. J. Tuma. 1985. Covalent binding of acetaldehyde to tubulin is associated with impaired polymerization. Hepatology (Baltimore). 5:1055.

8. Nomura, F., and C. S. Lieber. 1981. Binding of acetaldehyde to rat liver microsomes: enhancement after chronic alcohol consumption. Biochem. Biophys. Res. Commun. 100:131-137.

9. Medina, V. A., T. M. Donohue, M. F. Sorrell, and D. J. Tuma. 1985. Covalent binding of acetaldehyde to hepatic proteins during ethanol oxidation. J. Lab. Clin. Med. 105:5-10.
10. Mauch, T. J., T. M. Donohue, R. K. Zetterman, and M. F. Sorrell. 1985. Covalent binding of acetaldehyde to lysine-dependent enzymes can inhibit catalytic activity. Hepatology (Baltimore). 5:1056.

11. Lumeng, L., and R. G. Miter. 1985. Formation of acetaldehyde-hemoglobin adducts in vitro and in vivo demonstrated by high performance liquid chromatography. Alcohol. Clin. Exp. Res. 9:209.

12. Stevens, V. J., W. J. Fantl, C. B. Newman, R. V. Sims, A. Cerami, and C. M. Peterson. Acetaldehyde adducts with hemoglobin. 1981. J. Clin. Invest. 67:361-369.

13. Tuma, D. J., T. M. Donohue, V. A. Medina, and M. F. Sorrell. 1984. Enhancement of acetaldehyde-protein adduct formation of $\mathrm{L}$ ascorbate. Arch. Biochem. Biophys. 234:377-381.

14. Israel, Y., E. Hurwitz, O. Niemela, and R. Arnon. 1986. Monoclonal and polyclonal antibodies against acetaldehyde-containing epitopes in acetaldehyde-protein adducts. Proc. Natl. Acad. Sci. USA. 83:7923-7927.

15. Hoerner, M., U. J. Behrens, T. Worner, and C. S. Lieber. 1986. Humoral immune response to acetaldehyde adducts in alcoholic patients. Res. Commun. Chem. Pathol. Pharmacol. 54:3-12.

16. Lin, R. C. 1986. Quantification of apolipoproteins in rat serum and in cultured rat hepatocytes by enzyme-linked immunosorbent assay. Anal. Biochem. 154:316-326.

17. Tsang, V. C. W., J. M. Peralta, and A. R. Simons. 1983. Enzyme-linked immunoelectrotransfer blot techniques (EITB) for studying the specificities of antigens and antibodies separated by gel electrophoresis. Methods Enzymol. 92:377-391.

18. Lowry, O. H., N. J. Rosebrough, A. L. Farr, and R. J. Randall. 1951. Protein measurement with the folin phenol reagent. J. Biol. Chem. 193:265-275.

19. Lieber, C. S., and L. M. DeCarli. 1982. The feeding of alcohol in liquid diets: two decades of applications and 1982 update. Alcohol. Clin. Exp. Res. 6:523-531.

20. Lumeng, L., and T. K. Li. 1986. The development of metabolic tolerance in the alcohol-preferring rats: comparison of forced and free-chronic drinkings of ethanol. Pharmacol. Biochem. Behav. 25:1013-1020.

21. San George, R. C., and H. D. Hoberman. 1986. Reaction of acetaldehyde with hemoglobin. J. Biol. Chem. 261:6811-6821.

22. Sober, H. A., editor. 1970. CRC Handbook of Biochemistry. 2nd ed. The Chemical Rubber Co., Cleveland, OH. C-247. 